\title{
El libro y la censura durante el franquismo: Un estado de la cuestión y otras consideraciones
}

\author{
J. ANDRÉS DE BLAS *
}

\begin{abstract}
RESUMEN
Contra la afirmación, que ya amenazaba con volverse lugar común, de que «la censura del libro en el periodo franquista ha sido ya muy estudiada", este artículo sostiene la hipótesis contraria. Para ello, se ha realizado un estudio del estado de la cuestión que se ha procurado exhaustivo, en tanto la censura afecta tanto al emisor como al receptor $y$ por ende al propio texto. En el mismo se apuntan también algunas causas de ese desconocimiento, y entre ellas la confusión terminológica existente entre "censura" y "represión cultural", realizando, en este último caso, algunas teorizaciones que intentan definir con precisión ambos términos. Finalmente, se aporta una bibliografia que podría servir de punto de partida para otras investigaciones.

\section{ABSTRACT}

Contrary to the statement threatening to become a granted assumption - that the books censorship during Franco's regime has already been well studiedthis article holds the opposite hypothesis. Since the censorship affects in the same way both the transmitter (the author) and the receiver (the reader), therefore also the text itself, a thorough research about the heart of the matter has been carried out. Some of the reasons for the lack of knowledge about this question are also ponted out in this article being one of them the terminological confusion between "censorship" and "cuitural repression". Regarding this last issue and in order to define accuarately both terms, some thories have been developed. Finally, a bibliography maybe useful as a starting point for furthr research is included
\end{abstract}

* Departamento de Historia Contemporánea. (UNED). 


\section{PALABRAS CLAVE}

Franquismo, cultura, libro, censura, represión cultural, autocensura, "otras censuras", texto censurado, lector, estado de la cuestión.

\section{KEYWORDS}

Franco's regime, culture, book, censorship, cultural represion, selfcensorship, other censorship, censored text, reader, heart of the matter.

Ciertamente no será ocioso comenzar este artículo intentando precisar que es lo que en él se entiende por censura, y hacerlo vinculándolo al tema que nos ocupa: el mundo del libro. No será ocioso porque pensamos que una causa directa de la ausencia de estudios sobre el tema, guarda íntima relación con la concepción que, a nivel de mera opinión general o de un modo algo más específico entre quienes se han dedicado a estudiar la cultura del período considerado, se tuvo y se sigue teniendo de la misma.

A este nivel, básicamente se detectan tres posiciones: el lugar común, la postura minimalista y, como contraposición, la postura maximalista. $Y$ así, en primer lugar se constata una obligada mención, siquiera sea por no preterir lo insoslayable. Son menciones a la censura que no se articulan con ninguna consecuencia o efecto de la misma. Su misma frecuencia termina por hacer opaco su alcance y relega el tema "a la categoría de los lugares comunes" ".

La segunda postura es la posición "minimalista", aquella que se esfuerza en demostrar la levedad de su incidencia respecto a la producción cultural. Esta posición se puede considerar correlativa a aquellos que proclaman que la cultura "disidente" no partió de un punto cero, o niegan la existencia de un «páramo cultural». Su argumento principal es que la censura es universal y por otro lado, y apoyándose en datos supuestamente fehacientes, reducen su incidencia al dato cuantitativo?

1 Así para el tema literario, válido también a nivel general, y en una alusión que no ha perdido nada de su vigencia, leemos: "la frecuencia de las referencias diseminadas a lo largo y ancho de cualquier libro sobre literatura contemporánea está en relación inversa al peso de las publicaciones especializadas y, de no cambiar la situación, éstas últimas acabarán sirviendo de sucedáneo que retrasará indefinidamente la puesta en marcha de otras investigaciones". ABELLAN, MANUEL L., Fenómeno censorio y represión literaria. Diálogos hispánicos de Amsterdan, $\mathrm{n} .{ }^{\circ}$ 5, 1987, pp. 5-25.

${ }^{2}$ Así para el caso literario se pueden leer afirmaciones de este tipo: "la llegada de la democracia a finales de 1975 — con la supresión de la censura oficial y la vuelta de los exiliados, entre otras consecuencias - no trajo consigo el esperado o prometido florecimiento ya que (como era dado suponer) no existian aquellas novelas de subido mérito que tantos autores mantenían guardadas de la ira censorial; la marcha del género, superados desencantos y exageraciones, ha sido (y contirúa siéndolo) normal, sin ruptura". Martinez CaChero, J. M. ${ }^{\star}$. Historia de la novela española entre 1936-1980. Historia de una aventura, Madrid, Castalia, 1985, 2. ${ }^{\mathrm{a}}$ ed., p. 11. 
La tercera posición es "maximalista", ocurre entonces que censura y producción cultural vienen a convertirse en términos poco menos que sinónimos. El término se torna omniabarcante y pura tatutología ya que por su indistinción es incapaz de explicar cualquier aspecto de la misma. Es el nivel de la denuncia, donde se percibe cierto eco de resentimiento ${ }^{3}$. Es evidente que estas tres posiciones desactivan cualquier interés por el tema, y conducen a un callejón sin salida en lo que al estudio del mismo se refiere ${ }^{4}$.

Entre quienes han estudiado con mayor profundidad el fenómeno de la censura, existe una adscripción, tácita o de hecho, a la definición que de la misma da M. L. Abellán: “Por censura hay que entender el conjunto de actuaciones del Estado, grupos de hecho o de existencia formal capaces de imponer a un manuscrito o a las galeradas de la obra de un escritor - con anterioridad a su publicación- supresiones o modificaciones de todo género, contra la voluntad o el beneplácito del autor". En el mismo artículo, y más adelante, Abellán relaciona esos "grupos de presión", "con los medios de difusión de prensa y radio" " 5 . Traemos a colación la definición apuntada porque aunque es evidente que lo que en ella se define es la "censura institucional", censura que aunque teóricamente es el aspecto central del que se ocupan los estudios sobre censura, de hecho en la práctica dichos estudios operan con muchos más presupuestos. El resultado es una confusión entre conceptos que aunque interrelacionados, en nada benefician a la hora de definir campos de estudio precisos. $Y$ ese es un aspecto disuasorio, en otro orden de cosas, pero de resultados similares, a la hora de afrontar un estudio sobre la censura. El problema de tal definición es que se trata, por así decirlo, de una definición ya adjetivada. Pero con anterioridad a la censura referida a un período cronológico concreto -inseparable de un modo de actuar y de unos efectos determinados-cabe tratar de definir la censura en sí misma, y hacerlo diferenciándola del concepto de represión cultural con el que a menudo se la confunde.

\footnotetext{
3 A modo de ejemplo, se habla asi de "censura implacable". CAStellet, J. M. ${ }^{a}$, Literatura, ideología y politica, Barcelona, Anagrama, 1976., p. 6.

4 No menos perniciosas son aseveraciones del tipo: "la situación de la censura en España ha sido ya muy estudiada". Con ella el autor se refería obviamente a los medios de información, e incluso pensamos que a la censura en el cine o en el teatro. Conviene recoger también esta opinión porque es también opinión común. Pero si puede ser valida para los casos mencionados, yerra en lo que al mundo del libro se refiere. Timoteo Álvarez, J., "La información en la era de Franco: Hipótesis interpretativa», en Historia de los medios de comunicación en España. Periodismo, imagen y publicidad (1900-1990), Timoteo Álvarez y otros, Barcelona, Ariel, 1989, pp. 221-230, p. 224.

5 ABELLAN, M. L., "Censura y autocensura en la producción literaria española". Nuevo Hispanismo, $\mathrm{n} .{ }^{\circ} 1,1982$, pp. 169-180
} 
Ha sido en el campo del psicoanálisis donde más se ha teorizado sobre ambas cuestiones, y así podemos leer que: «El inconsciente es un discurso que fue pronunciado "en persona", en la primera sobre todo. Es muy probable que haya sufrido modificaciones debidas a la represión, otras las sufre con ocasión del retorno a la conciencia por la labor de la censura" ${ }^{6}$. $Y$ del mismo modo, que la represión puede definirse como uel proceso mediante el cual determinadas representaciones son rechazadas de la conciencia y mantenidas en el inconsciente" ${ }^{7}$. Lo que queda claro, en primer lugar, es que censura y represión son dos conceptos interrelacionados pero diferenciados. En segundo lugar, y teniendo en cuenta que la referencia a lo inconsciente supone hablar de un sentido susceptible de ser actualizado - verbalizado más bien, al unir la representación de cosa (la única que existe en lo inconsciente) a la de palabra-, estamos hablando lisa y llanamente de una borradura, de algo cuyo acceso nos es negado, prohibido. En tercer lugar, que la represión es previa a la censura, pues no tendría sentido que existiera un guardián que no tuviera nada que guardar. Finalmente, y en cuarto lugar, que to reprimido no puede acceder a la conciencia nunca como tal, pues unir representación de cosa - significante - y representación de palabra - significado - implica la entrada en un universo de sentido, acceso al orden del mundo, del logos. En ese pasaje, y cuando lo reprimido retorna, se sitúa el aduanero censor, causa de que lo que pasa lleve necesariamente la "marca» del lugar por el que ha transitado ${ }^{8}$.

Por analogía, cuando a nivel social se habla de represión sin más calificativos, tácitamente se está de acuerdo en que nos referimos a la represión física: eliminación definitiva si se trata de una muerte, eliminación temporal si se trata de un encarcelamiento, en su forma más radical. $Y$ todas las otras formas - por ejemplo a través de las depuraciones- que ejercidas sobre un individuo, logran eliminar, borrar la potencialidad de éste de ser portador y portavoz en lo social de un contenido, de un pensamiento en última instancia.

En este sentido, vale para los libros lo que vale para los hombres, y por tanto la idea de represión cultural remite a lo prohibido sin más, sea a consecuencia de su destrucción o de su inaccesibilidad por uno u otro mo-

\footnotetext{
6 Rifflet-Lemaire, Anika, Lacan, Barcelona, Edhasa, 1971. p. 219.

Gómen PIN, Víctor, El reino de las leyes. Orden freudiano, Madrid, Siglo XXI, 1981, p. 32.

8 Cuando se habla de que la censura es universal, en última instancia lo único que se quiere decir es que ésta es a nivel ontogénico algo estructural, constitutivo del ser humano, por eso su destino es reaparecer. Ahora bien, reaparecer repitiéndose en la diferencia. Es decir, ningún peligro de negar el dato histórico, sólo el intento de no operar sobre una exclusión.
} 
tivo, inaccesibilidad definitiva o durante un período de tiempo suficiente para que sea significativo, si la inaccesibilidad es temporal.

Todo ello sin perjuicio de que la censura tenga en ocasiones - sin que esto sea lo propio de ella- "efectos jurídicos represivos, como el secuestro, las sanciones penales o administrativas o las responsabilidades civiles" ${ }^{9}$, o en otro orden de cosas, la denegación dada a la edición de un libro. Lo que queda claro respecto a la represión como característica principal es que delimita claramente un espacio permitido y otro prohibido, dos espacios escindidos, muro de Berlín si no fuese por la relación dialéctica que entre ambos espacios introduce la censura ${ }^{10}$.

De la censura se dijo que se situaba en ese lugar de obligado pasaje, cuando lo reprimido retornaba a la conciencia. Pasaje que impondrá un peaje, pues no hay cesura sino censura: "Lo propio de la censura, y una de sus características más notables (...) es verse superada a cada momento, sufrir un constante "volteo", y es que de hecho la censura no es más que un amplio conjunto de volteos, de remolinos: "barra" todavia, pero igual que en la desembocadura de ciertos rios, por donde pasa el agua bien o mal». Hecho que presupone que "de la censura, sólo sabemos sus fracasos. Sin embargo, lo opuesto es igual de verdadero y acaso importe más: los fracasos de la censura establecen el saber que tenemos de ella, de modo que (después del descubrimiento freudiano) algo sabemos a fin de cuentas. $" 11$

En la citada definición de Abellán se habla de "supresiones o modificaciones", es decir - y sin que esto sea indicio de la benevolencia de la censura-, el mensaje circula, circula aún en el peor de los casos, cuando a la censura nos referimos. Pero ocurre que la definición de Abellán no es en realidad una definición, sino una confusión metonímica entre el efecto en tanto censura administrativa - las supresiones y modificaciones- y quien lo produce. O por decirlo de otra manera, se confunde la fábrica con lo fabricado. Pero por otro lado, tampoco la confusión metonímica es

9 GonzÁlez BAllesteros, Teodoro, Aspectos juridicos de la censura cinematogrática en España, Madrid, Univ. Complutense, 1981. p. 27.

10 La etimología latina del vocablo represión confirma este significado de separación. Asi, del verbo premo, -is, -ere, pressi, pressum: oprimir, apretar, coger fuertemente, derivaria con la adición del prefijo re -con el significado, entre otros, de separación-el verbo reprimo, -is, -ere, pressi, pressum: hacer retroceder oprimiendo, impedir avanzar, detener, retener, refrenar, reprimir. Blánquez, Diccionario latino-español.

11 Metz, Christian, Psicoanálisis y cine. El significante imaginario, Barcelona, Gustavo Gili, 1979, p. 216. Para el tema de la censura en el cine enfocado desde un punto de vista psicoanalitico veánse las pp. 199 y ss. 
total, pues en ella se oblitera el efecto que produce sobre aquello que autoriza, y tampoco se tiene en cuenta que si por un lado coacciona, por el otro también autoriza. Tal definición confirma así la cita anterior de que "de la censura sólo conocemos sus fracasos", es decir, sus incidencias. $Y$ asi, los estudios sobre censura, en un sentido general, deducen sus efectos, y su modo de proceder de aquellas galeradas o manuscritos que tuvieron problemas en censura. $Y$ aquellos otros que se ocupan de un autor, o de un conjunto de obras determinado, sólo pueden ocuparse de él en virtud de estas mismas incidencias ${ }^{12}$.

La censura, mal que pese a quienes la reducen a un aspecto represivo, implica una situación dialógica: con la censura estamos todavía en el plano del discurso, cosa que no ocurre con la represión en la que uno de los dos polos comunicativos (el "otro") ha sido suprimido. O más bien negado, pues existe de modo latente o potencial: es el discurso franquista que en su negativa le hace continuamente reaparecer. $Y$ así al término de la guerra el enemigo real se convierte en enemigo imaginario, no menos amenazante en un paranoico discurso oficial, pero no menos necesario como coartada justificadora para el mantenimiento del poder. $Y$ estar en el plano del discurso implica un grado de tolerancia - con las gradaciones que se quiera, pero tolerancia al fin y al cabo- pues entre lo permitido y lo prohibido no hay fractura sino una relación dialéctica que, siguiendo a Neuschäfer, "viene determinada por la contradicción entre ocultación/revelación por una parte, y descubrimiento/ revelación por otra» ${ }^{13}$. Plano del libro como texto que a la censura responderá con una específica estrategia discursiva.

Por otro lado, la tantas veces aludida arbitrariedad o ambigüedad de la censura confirma precisamente este hecho: la imposibilidad de fijar una norma precisa, es decir, un espacio de separación definido entre lo prohibido y lo permitido.

Concebir la censura de este modo, tiene ventajas a la hora de considerar el discurso que promueve, y del mismo modo pone en interrelación dos planos de actuación del organismo censorio, a nuestro juicio, insepa-

12 No se quiere decir con esto que no quepa un estudio de la censura institucional en sí misma, lo que se quiere apuntar con ello es simplemente el reconocimiento de que un estudio tal sólo es un estudio parcial, ya que si la incidencia de la censura se hubiese de calibrar por el aspecto cuantitativo -libros obligados a ciertas modificaciones o libros prohibidos- con ello sólo se daría cuenta de la levedad de sus efectos. Así lo confirman estudios llevados a cabo por ejemplo por Abellán.

13 Neuschäfer, Hans-Johg, Adiós a la España eterna. La dialéctica de la censura. Novela, teatro y cine bajo el tranquismo, Barcelona, Anthropos, 1994, p. 55. 
rables, pues no hay que olvidar que su tarea no es solamente eventualmente prohibitiva sino también autorizadora. $Y$ no es sólo que ambos planos hayan de ser tenidos en cuenta para un análisis cabal, es que resultan inseparables, ya que la función de lo permitido - lo que puede leerse-, independientemente de su contenido, es solapar lo que se prohibe o se ha hecho inaccesible - lo que no puede leerse-. Y esto ocurre porque asi como no hay a priori necesidad de prohibir - aunque esta necesidad fue sentida y practicada por el Estado franquista - si la hay de autorizar, pues no hay Estado que se precie que pueda prescindir de la cultura, ello por no hablar de los intereses materiales puestos en juego.

Reducir la censura a sus positivaciones, a sus evidencias, es sustraerse a las otras incidencias de la censura, más sutiles, menos manifiestas, pero a mi juicio, mucho más importantes, en tanto la censura implica un modo peculiar de codificación, difusión y recepción del mensaje en el campo de lo que puede leerse. Es decir, supone también la consideración de la autocensura, de las "otras» censuras y de ese, hasta hace poco, tercero excluido: el lector. $Y$ todo ello considerado dentro de un aparato o entramado sociocultural específico.

La formación de ese entramado cultural es coetáneo a los primeros momentos de la Guerra Civil, y se continuará durante la misma y con posterioridad a ella. Acorde con el principio genérico de creación de un "nuevo" Estado, se produce en este campo un intento estatal de controlar todos y cada uno de sus componentes. $Y$ así, la enseñanza, la investigación, los medios de comunicación y la producción artística, junto al personal encargado de su implementación fueron a todos los niveles objeto de una subversión legislativa respecto al precedente republicano. La estrategia de control adquiere, por otro lado, un marcado carácter dicotómico: una labor destructiva de la producción cultural anterior considerada inasimilable, y una labor positiva que no consiste tanto en la creación de una "nueva" cultura, como en colmar un espacio previamente vaciado, creando la expectativa de un «resto" genuino, y a la espera de una producción cultural que cubra ese vacío. Se trata de la proclamación de una autoctonía cultural sui generis como pauta interna a seguir, correlativa a un marcado desdén por la producción foránea ${ }^{14}$. Teóricamente y en principio se trataba de eso, otra cosa es lo que ocurre luego en la práctica concreta y las variaciones que en el transcurso de la postguerra se irán produciendo.

\footnotetext{
i4 En este sentido parece que para referirse al periodo inicial cuadra mejor la idea de la existencia de un modelo cultural autárquico, y no la denominación de un modelo de cultura imperial, ya que dicha denominación sólo refleja un aspecto de la misma.
} 
En cuanto a la política aplicada al libro, en virtud de lo que se ha ido refiriendo y en relación al tema que nos ocupa, pueden delimitarse de modo general dos etapas: una inicial, que coincide grosso modo con la Guerra Civil, en la que prima la represión y que coexiste con la censura; y una segunda, que se extiende con variaciones a lo largo del franquismo, que es la de la censura propiamente dicha. La primera etapa es correlativa a la segunda, y en ella se realiza la "criba» respecto a la producción libresca anterior, al tiempo que la nueva producción queda sujeta a la censura. Aunque la censura carga inicialmente con tareas represivas, realiza una labor "censoria" propiamente dicha. Las propias disposiciones legislativas por su parte delimitan claramente estos espacios de actuación, creando organismos encargados de la censura - previa, y por ende de la producción por venir- al tiempo que se dan disposiciones represivas en torno al libro -ya existente- y se crean, ad hoc, unas comisiones depuradoras destinadas a desaparecer más tarde. Es decir, las medidas que se toman respecto al libro son inicial y alternativamente preventivas y represivas ${ }^{15}$.

Es a partir de esta distinción entre represión y censura cuando cabe hablar con propiedad de autocensura, de las "otras" censuras y del efecto de la censura sobre el receptor-lector, ¿pues cómo referirse a estas cuestiones a partir de una virtualidad actuante que, en el caso de la represión, se quedaria sin objeto?

Por otro lado, Abellán define la autocensura como: "las medidas previsoras que un escritor adopta con el propósito de eludir la eventual reacción adversa o la repulsa que su texto pueda provocar en todos o algunos de los grupos o cuerpos del estado capaces o facultados para imponerle supresiones o modificaciones con su consentimiento o sin él». Si tal definición puede considerarse válida en lo que a la autocensura se refiere - - entendiendo el término en un sentido etimológico-, son más cuestionables las subdivisiones que estable de la misma, distinguiendo entre una autocensura explicita y otra implícita, la última de las cuales subdivide a su vez en consciente e inconsciente. Por lo que toca a la censura consciente, la misma se define como: «las medidas tomadas por el escritor con anterioridad a la redacción de la obra, a medida que va escribiendo o una vez redactado el manuscrito (...) antes de su envío a censura"; pero lo que se advierte es que tal definición no se diferencia en nada de la defini-

\footnotetext{
15 Por ejemplo, una medida represiva por antonomasia es la creación de las Comisiones depuradoras de los centros de lectura - $\mathrm{O} 16 / 9 / 37$ - pero en todo momento otros organismos se encargan de la censura propiamente dicha: Delegación del Estado para Prensa y Propaganda, Delegación Nacional para Prensa y Propaganda, Subsecretaria de Prensa y Propaganda etc.
} 
ción preliminar aplicada a la autocensura en sí, o lo que es lo mismo, autocensura explícita y autocensura implícita consciente vienen a ser términos equivalentes ${ }^{16}$.

Por nuestra parte pensamos que el punto de partida para tratar de buscar una definición que sea operativa a la hora de investigar sobre la misma, pasa por una primera diferenciación, por otra parte ya reseñada por Abellán, entre dos campos interrelacionados pero claramente definidos: lo consciente y lo inconsciente. Asi lo entiende el psicoanálisis cuando leemos que hay dos formas de censura a nivel ontogénico: una que sería la del sueño que es automática y otra que genéricamente se puede asimilar al campo de la escritura y que sería "voluntaria" ${ }^{17}$. A partir de esta distinción queda de manifiesto la impropiedad — por contradicción in terminis - de referirse a la censura inconsciente como autocensura, y será por tanto preciso reservar estrictamente este término para lo que ocurre en el campo de la conciencia. Que la censura inconsciente quede fuera del campo de la Historia como ciencia auxiliar - aunque a veces se producen sorpresas-, no puede ser óbice para reconocer que sin el papel que juega la censura en las formaciones de lo inconsciente, la virtualidad actuante de la autocensura como producto de una coyuntura histórica quedaría desactivada. Es decir, que la autocensura toma su potencialidad factual de esa censura inconsciente, y que por tanto deben existir elementos que de algún modo - ¿cuál? - interconecte a ambas.

A partir de esta diferenciación, si parece pertinente referirse a la autocensura como concepto presente en dos tipos de fenómenos sociales, asimismo necesitados de diferenciación, o más propiamente hablando dos fenómenos de interacción entre el individuo en tanto autor -respondiendo a la censura social con su autocensura- y lo social. A este respecto parece claro que todo poder y toda sociedad sustentada en determinados valores genera cierto grado de censura, y en este sentido también se puede hablar de una censura social con un carácter de universalidad. Pero sobre este substrato cabe diferenciar otro tipo de fenómeno, no cualitativamente diferente, tomando como criterio el grado de violencia o coerción con el que la censura trata de imponerse. Es ese "plus" censurante puesto de manifiesto en determinadas coyunturas históricas el que arroja como saldo un objeto preciso y susceptible por tanto de ser investigado.

ib. Abellán, Fenómeno censorio...

Asi lo entiende S. Kofman en su trabajo sobre la concepción estética de Freud: «grande différence entre ces deux formes de censure: celle du rêve est automatique, celle des lettres est volontaire". KOFMAN, SARAN, L enfance de lart. Une interprétation de lesthétique freudienne, Paris, Galilée, 1985, p. 59. 
Por otra parte y tomando también como criterio el grado de violencia o coerción, es posible del mismo modo diferenciar entre la autocensura y esas otras posiciones de un autor que le llevan a transformar su texto - supuesto un texto originario, cosa por otro lado bastante problemática- de un modo intencional, por cuestiones estéticas y otras cuestiones, pero siempre por él asumidas.

Con la referencia a las "otras censuras" estamos hablando de una censura social o "censura segunda", con efectos asimismo represivos, cuya labor censurante queda fuera del campo de la censura en sí, de la censura como institución, y que atañe en buena medida al mercado del libro - de un libro ya censurado y autocensurado- como producto terminado y que habrá de difundirse, promocionarse y leerse. $Y$ decimos que en buena medida porque, por un lado la censura como institución también incide en este campo, por ejemplo autorizando un texto en tirada limitada o autorizándolo sólo en una edición de lujo, o prohibiendo su exhibición en los escaparates de las librerías, aspectos todos ellos que dificultarán la difusión del producto; y por otro porque el autor deberá de tener en cuenta estos condicionantes a la hora de escribir un texto. Pero más allá de ello podemos leer que en un primer momento "todas las imprentas y editoriales se vieron afectadas por las normas sobre censura y obligadas a subordinar su actuación al ideario político, patriótico, moral y religioso del "nuevo estado", con la finalidad de ganar la confianza del régimen y poder subsistir conservando su carácter de entidad privada" ${ }^{18}$. Ello supuso, entre otros efectos, que el editor -que es normalmente quien realiza los trámites de presentación de la obra a la censura - realizase una censura previa a la oficial y que tuviese buen cuidado de no presentar ningún texto que levantase las sospechas del censor, puesto que «la licencia y los cupos de papel a tarifa reducida del censor eran una doble espada de Damocles sobre sus cabezas" ${ }^{19}$. Del mismo modo, en este apartado de las "otras censuras" hay que tener en cuenta el papel jugado por la crítica que se encuentra mediatizada por "grupos de presión de hecho, de existencia formal algunos e informal otros, íntimamente relacionados con los medios de difusión de

18 ALted, Alicia, Política del Nuevo Estado sobre el patrimonio cultural y la educación durante la Guerra Civil española, Madrid, Dirección General de Bellas Artes y Archivo, 1984, p. 65. Y con posterioridad, en virtud de la Orden de $8 / 3 / 1941$ se obligará a las editoriales a la presentación semestral de sus planes editoriales, que podrán ser aprobados, modificados, suspendidos de modo transitorio o denegados. Orden vigente hasta el 21/9/1944.

19 ABELLÁN, M L., Censura y creación literaria en España (1939-1976), Barcelona, Península, 1980, p. 78. 
prensa y radio. Se desconoce totalmente el modo de reclutamiento de los practicantes de la crítica literaria, los criterios de selección de libros, (y) su adscripción ideológica” 20.

Igualmente cabría referirse en este apartado a la política del libro y a la política bibliotecaria. Sin entrar en más detalles, para ambos casos, será suficiente traer a colación algunas citas significativas de las que se puede deducir una postura oficial dirigista e intervencionista en torno al libro y con unos resultados que de modo general se pueden presuponer. Así en lo que atañe a la política del libro, implementada por el INLE ${ }^{21}$, y en lo que puede denominarse como una declaración programática, se dice: «el Instituto no puede limitarse a continuar, ni siquiera a renovar. Viene a implantar una política del libro o, mejor aún, a introducir en el dominio del libro la gran política de la Falange" ${ }^{22}$. Respecto a la política bibliotecaria -en cuya consideración se ha de tener en cuenta tanto lo que se ofrece como lo que estando disponible se rechaza- de nuevo se perciben esas líneas maestras que guían la cultura oficial de "vaciado cultural" y formación en los principios del Nuevo Estado, y de este modo es significativa la cita del que fuera jefe del Servicio de Archivos y Bibliotecas, Javier Lasso de la Vega, que concibe la misión de éstas, respecto al lector, como una tarea de: "enriquecer su mente con el máximo número de conocimientos útiles posibles para ponerla al servicio de Dios, de la patria, de sí mismo y de su profesión". Y la tarea de una pretendida ciencia bibliopsicológica, asimilada a la labor del farmaceútico, en un burdo conductismo, es estudiar "el libro, no bajo el aspecto de su importancia cultural (...) sino como una suerte de aparato, ingenio o instrumento psicológico que sirve para provocar, en el ser psíquico del lector, ciertas experiencias determinadas y complejas" ${ }^{23}$.

Asimismo se puede incluir en este apartado de las "otras censuras" lo referente a ediciones de autores foráneos en España: latinoamericanos

20 Ib. ABELLAN, Censura y autocensura... Y de modo similar, para el caso de la poesia, pero extensible al libro en general: "nadie juzga una obra, ni se preocupa siquiera de ella, sin tener previamente en cuenta la significación extraliteraria del autor (...) ocurre que cuanto más se silencian ciertos libros, más grotescos resultan los ditirambos que se tributan a otros. J. LECHNNER, EI cOmpromiso en la poesia española en el siglo XX, Leiden, Univers Press, 1975, p. 8.

21 El denominado Instituto Nacional del Libro Español, creado en virtud de la O/23/5/1939, con una fase transitoria en la que se denomina como Instituto del Libro Español, venía a sustituir a las anteriores Cámaras del Libro. Su labor principal, además de marcar las pautas editoriales y promocionar el libro español, consistía en servir de mediador entre las editoriales y la Administración.

${ }^{22}$ Cit. en Valeriano Bozal: Rev. Bibliografía Hispánica, n. ${ }^{\circ} 1$, mayo-junio, 1942 . Valeriano Bozal, "La edición en España. Notas para su historia", Rev. Cuadernos, Mayo, 1969. pp. 85-93.

23 AlTED, Alicia, Ob. cit., respectivamente, pp. 54 y 55 
sin traducción o autores traducidos. A este asunto nos referiremos luego al comentar las monografías escritas sobre el tema ${ }^{24}$.

Finalmente, uno de los efectos posibles de la censura sobre el lector - ese tercero excluido cuando de hablar de la censura se trata- sería perceptible a partir del tipo de textos que la censura genera. Si mantenemos la hipótesis de que una finalidad de la censura es desactivar toda disidencia, en correspondencia se puede presumir que con ello genera un tipo de lector "censurado" en esa misma potencial disidencia. Este lector se verá obligado a realizar una lectura "entre líneas" susceptible siempre de provocar malentendidos, y por eso podemos leer en una cita que consideramos válida para el lector en general, que a partir de 1939 "existe para el crítico el peligro de querer descifrar cuando no hay cifra y de leer lo que no se ha querido escribir ${ }^{25}$.

Hasta aquí se han intentado apuntar algunas de las causas que mantienen los estudios sobre la censura y el libro en un estado de desconocimiento. Del mismo modo se han querido ofrecer algunas definiciones que resulten operativas a la hora de abordar su estudio, y al hacerlo, se pudo comprobar como la censura, tras la represión inicial, afecta a modo de cortocircuito a todos los elementos implicados, en lo que de otra manera debería ser un proceso, peculiar, pero normal de comunicación. Seguidamente pasamos a comentar aquellos trabajos más significativos en lo que se refiere al tema que nos ocupa.

Respecto a la producción bibliográfica sobre el tema, lo primero que llama la atención es su parquedad, pero más allá de ello también el hecho de que éste haya sido abordado por sociólogos e investigadores vinculados de uno u otro modo al campo de la literatura, pero no por los historiadores que, en general, se han preocupado más por la censura en la prensa dada la vertiente política de la misma. Es cierto que el tema reclama un acercamiento interdisciplinario, pero no es menos cierto que el tema en-

24 Normalmente adscrita esta tarea, a falta de mayor confirmación, a las labores generales de la censura, durante un periodo de tiempo existió un organismo específico denominado Servicio de Inspectores de Traducción, creado en 1942

25 Ib.Lechner. Y del mismo modo: "cuando se habla de censura se tiene normalmente presente al escritor y es un grave error olvidarse del público. La censura es un acto perverso «per se» que no sólo influye directa y negativamente en el escritor, sino que to hace de una forma aplastante y demoledora sobre el público, repercutiendo esta incidencia nuevamente y de otra manera sobre el escritor. Ese término, tan cacareado, y muchas veces erróneo, de "exilio interior" quiere expresar las más de las mismas esta disociación entre creador y público, la ausencia de un espacio para dialogar, o sea para que la experiencia literaria se convierta en obra" MaTEO, Eduardo, Algunos problemas culturales de los años cuarenta en España, Rev. Spagna Contemporanea, $\mathrm{n} .^{\circ}$ 1. 1992, pp. 61-84. 
caja con idoneidad en esa rama de la Historia que es la Historia de la Cuttura. Aunque quizá el hecho no haya de extrañarnos tanto si se tiene en cuenta el escaso desarrollo de este campo en nuestro país, y de modo particular en lo que se refiere al mundo del libro durante el franquismo ${ }^{26}$. No nos referimos, claro está, a una Historia de la Cultura de corte tradicional, esa que estudia las diversas producciones de modo compartimentado y se rige por el principio del acontecimiento, sino a una Historia de la Cultura a la que, en una mayor pretensión de objetividad, deberían interesarle por principio todos los autores, libros y lectores. Frente a esa historia tradicional, el estudio del mundo del libro en sus diversos aspectos, tiene la ventaja, en tanto éste fue soporte fundamental de un saber codificado y transmitido de forma escrita, de enlazar transversalmente los diversos campos del saber, y articularlos en torno a ese elemento sin el cual no hubieran sido, o hubieran sido de otro modo: el libro.

Como se dijo, hacer un estudio del estado de la cuestión respecto a la censura es hacerlo sobre pocos autores y escasos trabajos, y la mayor parte de ellos centrados únicamente en el campo literario, hasta tal punto que, desmintiendo de modo radical la opinión común, uno podría empezar por preguntarse si hay "cuestión». En este sentido la extensa bibliografía que se da al final no debe llamar a engaño, pues sólo la considerada como básica realiza aportaciones relevantes al tema. Pero por otro lado, y con un afán de exhaustividad que abarcase todas las vertientes de estudio que implican al libro y la censura, hemos creído necesario allegar todas las referencias posibles, y ello por dos razones: para evitar el equívoco de confundir la cantidad con la calidad, ya que la mayor parte de lo escrito se realiza de modo coyuntural, sin documentación que lo avale, y no va más allá del testimonio superficial o la mera opinión personal; la segunda razón, es que, a pesar de lo dicho, en el estado actual de conocimiento sobre el tema aportan un complemento bibliográfico no del todo desdeñable.

Cronológicamiente el primer trabajo monográfico aparece en $1977^{27}$, y se centra en los efectos de la Ley de Prensa de 1966 sobre el mundo edi-

\footnotetext{
26 Con la excepción de los trabajos en torno al libro de texto, y de modo ennumerativo, se puede decir que faltan estudios respecto a la política oficial en torno al libro, la política bibliotecaria, el papel jugado por las editoriales oficiales y las editoriales privadas, el mercado del libro: interior y exterior, sobre la difusión en España de autores extranjeros, sobre el papel jugado por la crítica, sobre organismos como el INLE o el Sindicato de Artes Gráficas, y de modo especial estudios sobre la lectura y el lector. A falta de mayor precisión, se puede concluir que el desconocimiento en lo que al mundo del libro se refiere es importante.
}

27 Cisquella, Georgina, J. Luis Erviti y José A. Sorolla... 
torial. Aunque más que análisis lo que aporta es sobre todo información, posee el mérito de manejar fuentes hasta ese momento inéditas como eran los archivos de las editoriales, y recurre a la a entrevista con los editores, hecho que supone un nuevo viraje pues lo normal hasta entonces había sido centrar los efectos de la censura sobre el autor.

Tres años más tarde aparece el estudio de Abellán ${ }^{28}$, que sigue siendo el texto "clásico" por excelencia respecto a la censura, pues no hay trabajo que se escriba con posterioridad que no tenga en cuenta sus aportaciones. Autor de otros artículos fundamentales ${ }^{29}$ y organizador de encuentros ${ }^{30}$, Abellán sigue siendo la referencia fundamental en lo que al estudio de la censura, desde el punto de vista de la sociología literaria, se refiere. Su texto es pionero en el manejo de los archivos de censura ${ }^{31}$, fuente que, junto a una encuesta realizada a los escritores de la época, le sirven de base para escribir su texto. Con estos materiales estudia la organización, el funcionamiento y las incidencias de la censura respecto a los autores, los textos y las editoriales.

Desde la fecha de publicación del trabajo de Abellán, con la salvedad de los textos básicos producidos a raíz del Simposio sobre Censura y literatura

\footnotetext{
2B Censura y creación literaria en España (1939-1976).
}

29 Así en Censura y autocensura..., intenta una definición de ambos conceptos, y ofrece una periodización de las etapas y caracteristicas de la censura oficial. En Fenómeno censorio..., ofrece un estado de la cuestión desde un punto de vista histórico general y aporta algunas propuestas metodológicas. Posteriormente, en Problemas historiográficos..., vuelve a realizar un estado de la cuestión y centra su estudio en las "otras censuras". Finalmente, entre otros trabajos, hay que señalar el llevado a cabo junto a JEROEM OSKan, Función social de la literatura eclesiástica, respecto a la censura de libros ejercida por las autoridades eclesiásticas a título de "pastor de aimas" en diversas publicaciones católicas.

30 Simposio sobre Censura y literaturas peninsulares, celebrado en Amsterdam los días 2 y 3 de mayo de 1985

3t La primera persona que parece haber manejado estos archivos es MARTINEz CACHERO, Historia de la novela española..., cuya primera edición se realiza en 1973. En este sentido la primacía de Abellán se refiere a que es el primer investigador que los utiliza de modo exhaustivo y para un trabajo monográfico sobre la censura. Respecto a los archivos hay que señalar que son de libre acceso desde 1985, pero ello no se ha traducido en un incremento de los estudios sobre el tema, y asi ocurre, según me comunicó el personal alli empleado, que la mayoría de los expedientes no han sido jamás examinados. Por otro lado, hay que señalar que esta documentación, integrada ahora en los fondos de Cultura - Ministerio de Cultura - fue pasando, a modo de precedente documental, por los diversos organismos de los que dependió la censura. En ese largo periplo que se inicia en 1937 --fecha de la documentación más antigua - hasta su depósito definitivo en el Archivo Genera! de la Administración, la documentación fue sometida a diversos expurgos, cuyo alcance a falta de un inventario completo desconocemos. Este hecho ya había sido señalado por Abellán respecto a la documentación por el examinada en el MIT -Censura y creación...-. A título personal, en un cala realizada sobre los años 1937-1945, pude comprobar que aunque el número de expedientes que faltan decrece a medida que avanzamos en el tiempo, existen grandes lagunas documentales, con series completas perdidas y series a las que faltan un gran número de expedientes, y dentro de los expedientes expurgo de parte de la documentación que deberían contener. 
peninsulares de $1985^{32}$, se produce un vacío historiográfico de 8 años hasta la aparición de los trabajos de La Prade Douglas y Sánchez Reboredo ${ }^{33}$. El primero de estos trabajos estudia, a partir de los informes de los censores, las dificultades generadas por la censura para publicar la obra de Hemingway en España. Se trata del único trabajo monográfico hasta la fecha referido a un único autor. No obstante posee un valor paradigmático en lo que al campo de las "otras censuras" se refiere, ya que el caso de dicho autor es extensible de modo genérico a todos aquellos textos que fueron traducidos durante el período aquí considerado. Textos en los que, a la labor de poda de la censura, hay que añadir la actividad del propio editor, que llega a producir alteraciones e incluso supresiones completas de algunos pasajes para lograr el placet de la censura. La escasez de trabajos similares - con la salvedad del estudio de Romero-Dowing, que comentamos después- muestra hasta que punto desconocemos el alcance de ese filtrado, y como no sirve la simple nómina de autores traducidos y editados en España para evaluar el grado de apertura cultural. Es casi seguro que un cotejo minucioso con las ediciones originales produciría muchas sorpresas ${ }^{34}$.

El estudio de Sánchez Reboredo se centra en los efectos de la censura sobre el texto, pero no a partir de las supresiones, sino sobre el modo en que los recursos de la retórica literaria realizan esa operación dialéctica de trasvase de ideas a un lugar teóricamente no permitido. Tal hecho influirá en el lector obligándole a manejar una suerte de código semántico hecho de sobreentendidos y lecturas entre líneas. Como en el caso anterior se trata de un campo apenas estudiado ${ }^{35}$, y paradigmático de nuevo en tanto necesariamente esa operación de contrabando marcará de modo peculiar los textos producidos en el período.

En los primeros años de los 90 se publican cuatro trabajos monográficos que, en principio, pudieron hacer pensar que nos encontrábamos ante un cambio de tendencia significativo, pero tal esperanza queda frustrada a partir del momento en que se puede comprobar que desde el año 1994 - fecha de publicación del último de estos trabajos - no ha aparecido ninguna monografía sobre el tema. A ello hay que añadir, hasta donde hemos

32 Textos recogidos en el $n .^{\circ} 5$ de la revista Diálogos Hispánicos de Amsterdam, en 1987.

33 Respectivamente. The Censorship of Heminway in Spain y Palabras tachadas: retorica contra censura.

${ }_{34}$ Aunque en un momento temprano existió un Servicio de Inspección de Traducciones, luego estas tareas fueron, perdiendo su especificidad, transferidas a la actividad general de la censura. Se puede encontrar más información sobre el tema en: J. HuRTLEY: Josep Janés... y Translation in Postwar... M. Alpert, R. Lefere, y especialmente, en el estudio de J. C. Santoyo.

35 Sobre el mismo tema, véase: Neuschäfer, Ascunce Arrieta y Tino Villanueva. 
podido comprobar, la ausencia de trabajos en curso, lo que hace pensar en un nuevo estancamiento de la investigación sobre el asunto que nos ocupa.

El trabajo de Neuschäfer ${ }^{36}$-aunque no se centra únicamente en el mundo del libro- investiga, como en el caso de Reboredo, los efectos de la censura sobre el texto a partir de dos recursos fundamentales: la metáfora y la metonimia. Tal hecho supone constatar el enorme poder de la censura en tanto ésta es capaz de generar un discurso propio: "el discurso de la censura". Asimismo es reseñable en este trabajo su intención teorizadora - aspecto no tratado - sobre la censura a partir de los presupuestos del psicoanálisis.

Por su parte, la tesis de R. Dowing centra su estudio en la labor censoria llevada a cabo en la producción novelística latinoamericana, ya sea en textos importados o en textos publicados en España, entre los años 1939-1976. Desde un enfoque histórico-literario establece una periodización según el criterio de actuación de la censura y señala sus efectos generales, y en aquellas obras que tuvieron problemas con la censura, sus efectos particulares ${ }^{37}$.

Finalmente, sólo dos estudios, presentados como tesis doctorales, se ocupan de los efectos de la censura respecto a los nacionalismos históricos, constatando en ambos casos, además de un alto nivel de represión, la existencia, de una doble censura: la "ordinaria" y la idiomática regional. Se trata

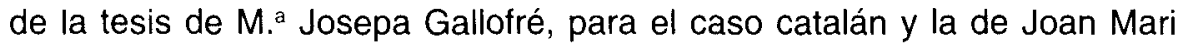
Torrealdi, para el caso vasco. M. ${ }^{a}$ Josepa Gallofré, sirviéndose de los archivos de censura y de la documentación aportada por las editoriales, analiza, como punto de partida, la purga de los fondos editoriales y de las librerías en 1939. Posteriormente establece una serie de etapas, plagadas de vicisitudes y dificultades, respecto a la edición de textos en lengua catalana, para deducir de ello la existencia de una política lingüistica y cultural especifica del franquismo. Por su parte, J.M. Torrealdai, a partir de los presupuestos de la sociología literaria, estudia tanto el libro en euskera como los libros de tema o/y autor vasco. Como en el caso anterior, y a partir de los análisis de los archivos de censura, establece una serie de etapas, en un contexto de control cultural. La ventaja, en ambos casos, de la reducción del ámbito territorial de estudio, a partir de la actividad de las Delegaciones Provinciales, permite la evaluación de todo tipo de textos, no sólo los literarios, como venía siendo

\footnotetext{
36 Es significativo tambièn el hecho de que 4 de las 8 monografias aqui comentadas, hayan sido escritas por autores extranjeros, hecho que agrava aún más, si cabe, la despreocupación a nivel nacional por el tema.

Sobre el mismo tema: Nuria FONS y ABELLAN: La censura franquista y los escritores katinoamericanos.
} 
habitual. $Y$ ello conlleva la posibilidad de poder acercarse a una comprensión global de la política cultural puesta en práctica por el franquismo de modo general, y la aplicada al libro, de modo particular ${ }^{38}$.

Cerrado el capítulo de monografias, es preciso reseñar la importancia de los artículos de Juan Beneyto: La censura... y el de Miguel Hernández, ya que ambos ocuparon cargos relevantes en el aparato de censura: el primero como Director de la Sección de Ordenamiento Editorial hasta enero de 1941, y el segundo como Director General de Cultura Popular en los años finales de existencia de la censura administrativa. Cada uno a su modo, ofrece el testimonio de quien fue conocedor directo de los hechos.

Igualmente hay que señalar la importancia del trabajo de Benito Bermejo, en tanto en él se logra configurar el organigrama, aportando datos sobre su funcionamiento y objetivos, de la organización de la Vicesecretaria de Educación Popular. Datos de los que tan necesitados andan los estudios sobre censura que con frecuencia se mueven en un terreno confuso en lo que a ello respecta.

Finalmente, y a otro nivel, hay que reseñar el interés de las entrevistas realizadas por Antonio Beneyto y Sergio Vilar, en tanto recogen los testimonios de diversos autores e intelectuales que realizaron su labor bajo la coacción de la censura. En una fecha tan temprana como 1964, S. Vilar propone a los autores preguntas tan «comprometidas» como las siguientes: "El arte ¿debe basarse únicamente en la libre actitud creadora del artista?, y ¿Cree usted que para el artista es necesaria una libertad personal y política absoluta?». Por su parte, A. Beneyto, trece años después, incluye asuntos similares pero abordados en el transcurso de una conversación. Quizá, uno de los aspectos más destacables, más allá del testimonio ofrecido, es la diferencia que se percibe respecto a las opiniones vertidas, ya que claramente se pasa del eufemismo y la alusión -o desde la imposibilidad de hablar de la censura con censura- a un planteamiento más concreto y directo de las incidencias de la censura en la labor creativa.

A modo de conclusión, se puede decir - si mantenemos la hipótesis de que la censura es uno de los rasgos principales de la cultura del período

\footnotetext{
38 Con la salvedad de los trabajos comentados, y otros llevados a cabo por los mismos autores, volvemos a encontrarnos con una carencia general de estudios respecto al tema. No obstante, para el caso catalán hay una bibliografía más extensa de autores que, al tratar el tema de la cultura, incluyen en su análisis la cuestión de la censura, son los casos de Benet y Massot i Muntaner. Otras referencias son los estudios llevados a cabo por SAMSO LlEnAS, ESTANISLAU TORRS, SOLE I SABATE y ABELLAN: Apunts... Para el caso gallego, con la salvedad del artículo de Losada Castro, y el texto de Carlos Fernández sobre Castelao, no tenemos conocimiento de ningún otro trabajo.
} 
franquista, y pensando también que nadie hasta la fecha ha demostrado lo contrario- que el desconocimiento de la misma ${ }^{39}$ redunda necesariamente en el desconocimiento de la cultura del franquismo. Finalmente, y más allá de las causas mencionadas, quizá haya que considerar una razón de fondo más determinante, en tanto examinar la cultura del periodo teniendo en cuenta los efectos de la censura supone, en cierto modo, realizar una "nueva" lectura de esa producción cultural. Una "nueva» lectura incómoda en tanto implicará reconocer a nivel personal, y en lo que a cada uno le atañe, el haber sido víctima de esa censura.

\section{BIBLIOGRAFIA BÁSICA 40}

\subsection{Monografias}

Abellán, Manuel L.: Censura y creación literaria en España (1939-1976), Península, Barcelona, 1980.313 pp.

Cisquella, Georgina, ERVITI J.L. y Sorolla, J. Antonio: Diez años de represión cultural. La censura de libros durante la Ley de Prensa (1966-1976), Anagrama, Barcelona, 1977.177 pp.

Gallofré , VIRGIL, M. Josepa: L'edició catalana ila censura franquista (1939-1962), Barcelona, Universidad Autóma, 1992. (Microficha). Edición en libro: L'edició catalana i la censura franquista (1939-1951), P'ublicaciones de L'Abadia de Montserrat, Barcelona, 1991. 1. vol. 542 pp.

39 Visto desde el prisma de la censura, o en su caso, de la represión cultural, faltan estudios que relacionen la censura con la política cultural, la politica bibliotecaria, la ideología, la labor de propaganda o la política aplicada al mundo del libro. Faltan asimismo estudios sobre la autocensura, sobre el "discurso de la censura", y sobre la incidencia de la misma en el mundo del lector. Respecto al organismo en si, faltan por determinar las implicaciones ideológicas de las diferentes familias políticas, su grado de mimetismo o, en su caso, su originalidad en relación a aparatos similares existentes en la Italia fascista o la Alemania nacionalsocialista. Del mismo modo, existe un alto grado de confusión respecto a la legislación, la organización y el funcionamiento.

40 Salvo quizá en lo que se refiere a la bibliografía básica, la clasificación de los textos que aquí se hace es, como toda clasificación, discutible. En el apartado ureferencias varias" y siguiendo una clasificación descendente según el criterio de importancia, se han incluido bastantes de los trabajos de autores que figuran en la ubibliografía básica", la razón ha sido que muchos de ellos quedan subsumidos en sus propias monografias. Un segundo grupo dentro de este mismo apartado queda constituido por autores que centran su atención en temas culturales pero que incluyen apartados referentes a la censura, a la edición censurada, a la autocensura, o a la represión cultural. En un tercer caso, se trata de aportaciones que, aunque se centran en la censura, son aportaciones secundarias. Finalmente, en el apartado "otras referencias" se incluyen trabajos que, aún siendo válidos en sí mismos, no aportan nada nuevo o lo hacen de modo tangencial, respecto a la bibliografía de los dos apartados anteriores. También es necesario precisar que, quizá con un criterio un tanto arbitrario, además de por razones de tiempo y espacio, no se han incluido los trabajos referentes a la censura teatral. La razón ha sido que el hecho de que el teatro sea concebido para ser representado, aún cuando una obra de teatro pueda leerse como texto, introduce con ello una variante que queda fuera del campo del libro estrictamente hablando. Por otro lado, de seguir ese criterio amplio, no hubiera habido ninguna razón para no incluir por ejemplo, los guiones de cine y de radio, o los libretos de óperas y zarzuelas o los textos musicales, temas por otra parte, con la salvedad de los guiones de cine, intocados desde el punto de vista de la censura. 
La Prade Douglas, Edward: The Censorship of Heminway in Spain, Ann Arbor, Michigan, 1988. $217 \mathrm{pp}$.

NEUSCHÁFER, Hans-Jörg: Adiós a la España eterna. La dialéctica de la censura. Novela, teatro y cine bajo el franquismo, Anthropos, Barcelona, 1994. 367 pp. (1. ${ }^{*}$ ed.: Macht und ohnmacht der zensur, Stuggart, 1991).

ROMERO DOWNING, Gloria: Los escritores latinoamericanos y la censura franquista: 1939-1976, Ann Arbor, Michigan, 1994. 342 pp.

Sanchez Reboredo, José: Palabras tachadas: rétorica contra censura, Instituto de Estudios Juan Gil Albert, Alicante, 1988. 169 pp.

TORREAldaI NABEA, Joan Mari: La censura gubernativa y el libro vasco (1936-1983): análisis de los informes del lectorado de Bilbao, Tesis, Universidad de Deusto, 1991.

\section{Articulos en revistas o libros}

ABELLAN, M. L.: "Censura y autocensura en la producción literaria española", Nuevo Hispanismo, n. ${ }^{\circ} 1,1982$, pp. 169-180.

ABELLÁN, M. L.: "Fenómeno censorio y represión literaria", Diálogos Hispánicos de Amsterdam, n. ${ }^{\circ}$, 1982., pp. 169-180.

Abellán, M. L.: “Problemas historiográficos en el estudio de la censura literaria del último medio siglo», República de las Letras, n. ${ }^{\circ} 25,1989$, pp. 20-27.

Abellan, M. L.: "Sobre censura. Algunos aspectos marginales", Ruedo lbérico, n. ${ }^{\circ} 49-50,1976$, pp. 137-138.

ABELLAN, M. L.: "La censura franquista y los escritores latinoamericanos", Letras Peninsulares, ก. ${ }^{\circ}$ 5.1, 1992, pp. 11-21.

ABELLAN, M. L. y OSKAM, Jeroen : «Función social de la censura eclesiástica. La crítica de libros en la revista "Ecclesia" (1944-1951)", Cuadernos Interdisciplinarios de Estudios Literarios, ก. ${ }^{\circ} 1,1989$, pp. 63-118.

Beneyto Pérez, Juan: "La censura en los primeros años del franquismo. Las normas y los hombres", Diálogos Hispánicos de Amsterdam, n. ${ }^{\circ}$ 5, 1987, pp. 27-40.

Bermejo SÁnCHEz, Benito. "La Vicesecretaria de Educación Popular (1941-1945): un "ministerio" en manos de Falange", Rev. Espacio, Tiempo y Forma ( $H .{ }^{a}$ Contemporánea), 1991, pp. 73-96.

Cruz Hernandez, Miguel: “Del deterioro al desmantelamiento: los últimos años de la censura de libros", Diảlogos Hispánicos de Amsterdam, n. ${ }^{\circ}$ 5, 1987, pp. 28-41.

OSKam, Jeroen: "Investigaciones sobre la Historia Cultural Contemporánea de España", www.geocities.com.

ROMERO-DOWNING, Gloria: "La edición de los autores latinoamericanos en el contexto de la España de los cuarenta», Cuadernos Interdisciplinarios de Estudios Literarios, n. ${ }^{\circ 1}$, 1994, pp. 121-128.

TorRealdal Nabea, J. Mari: "Censura y literatura vasca", Diálogos Hispánicos de Amsterdam, n. ${ }^{\circ} 5,1987$, pp. $65-97$.

\section{REFERENCIAS VARIAS}

ABELLAN, M.L.: “Censura y producción literaria inédita", insula, $n .^{\circ} 395,1976$, p..3.

ABELLAN, M.L.: “Censura y práctica censoria», Sistema, n. ${ }^{\circ} 22,1978$, pp. 29-52.

ABELLAN, M.L.: «Análisis cuantitativo de la censura bajo el franquismo (1955-1976)", Sistema, n. ${ }^{\circ} 28,1979$, pp. $75-89$.

ABELLAN, M.L.: "El discurso prohibido por la censura durante el primer franquismo», en Discurso erótico y discurso transgresor en la cultura peninsular, siglos XI al XX. Díaz-Diocaretz, Myriam e Iris M. Zabala (coors.), Tuero, Madrid, 1992. pp.183-198.

AbelLán, M.L.: "Los últimos coletazos de la censura", Diario 16, n. ${ }^{\circ} 16, \mathrm{pp} .438-440$

ABELLAN, M.L.: "Literatura y moral en el primer franquismo", Papers: rev. de Sociologia, $n, 21$, 1984, pp. 153.172. 
Álamo Felices, Francisco: La novela social española. Conformación ideológica, teoria y crítica, Serv. De Publicaciones de la Univ. de Almería, Almeria, 1996, pp. 79-107.

Álvarez PALACIOS, Fernando: Novela y cultura española de posiguerra, EDICUSA, Madrid, 1975. pp.163-267.

Beneyto, Antonio: Censura y política de los escritores españoles, Plaza \& Janés, Barcelona, 1977, $292 \mathrm{pp}$.

BENEYTO, Juan: "La politica de comunicación en España durante el franquismo", Rev. de Estudios Políticos, $\mathrm{n}^{\circ} 11,1979$.

FeRnandez, Carlos: La persecución de Castelao durante el franquismo, Ediciones do Castro, A Coruña, 1986, $130 \mathrm{pp}$.

Fons PaAts, Nuria: La novela hispanoamericana en España, 1962-1975, Tesis, Universidad de Granada, 1995

GallofaE I VIRGiLI, M. Josepa: "Entre la proscripció i la retallada. Autors catalans en llengua castellana, 1942", Cuadernos Interdisciplinarios de Estudios Literarios, n. ${ }^{\circ} 1,1989$, pp. 165-175.

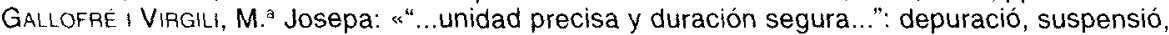
prohibició. Barcelona, 1939", Diálogos Hispánicos de Amsterdam, n. ${ }^{\circ}$, 1990, pp. 183-190.

GallofRÉ I VIRGILI, M. a Josepa: "La cojuntura de 1951 i els criteris de censura", en Miscel.lània d homenatge a Josep Benet, Abadia de Montserrat, Barcelona, 1991, pp. 621-630.

Gallofré I VIRGILI, M. ${ }^{a}$ Josepa: "Una petita memòria feta en el gran moviment", Randa, $n .{ }^{\circ} 28$, 1991, pp. 167-181.

HURTLY, Jacqueline: Josep Janés. El combat per la cultura, Curial, Barcelona, 1986, pp. 274 311.

LA Prade Douglas, E.: "The Francoist Censorship of Hemingway's Works about Spain", Cuadernos Interdisciplinarios de Estudios Literarios, $n{ }^{\circ} 12$.

LOSADA CASTRO, Basilio: "Literatura gallega y censura franquista", Diálogos Hispánicos de Amsterdam, n. ${ }^{\circ} 5,1987$, pp. 57-63.

Martinez Cachero, J. M.: Historia de la novela española entre 1936-1980, Castalia, Madrid, 1985 (pp. 102-113, 243-305, 379-387 y 395-403).

MATEO, Eduardo: “Algunos problemas culturales de los años cuarenta en España", Rev. Spagna Contemporanea, n. ${ }^{\circ} 1,1992$, pp. $61-84$.

Paramo, Pedro, Bayón, M., y Fernandez, P.: "Viaje al centro de la censura (1939-1975)", Cambio $16, \mathrm{n}^{\circ} 718,1985, \mathrm{pp} .47-54$.

Romero-Downing, Gloria: “Una edición de Poemas de las madres de Gabriela Mistral ante la censura franquista", Hispanic Journal, n. ${ }^{\circ} 17,1996$, pp. 47-53.

TorRealday, J. Mari: La censura de Franco y los escritores vascos del 98, Ttarttio, Donostia, 1998. $121 \mathrm{pp}$.

VILAR, Sergio: Manifiesto sobre arte y libertad. Encuesta entre los intelectuales y artistas españoles, Fontanella, Barcelona, 1964, 376 pp.

\section{OTRAS REFERENCIAS}

Ascunce Arrieta, J. Ángel: "Recursos poéticos frente a censura: "Hija de Yago" de Blas de Otero", Letras de Deusto, n. ${ }^{\circ} 44,1989$, pp. 55-68.

BENET, Josep: Cataluna bajo el régimen franquista: informe sobre la persecución de la lengua y la cultura catalana por el régimen del general Franco, Blume, Barcelona, 1979, pp. 248-253 y 347.

CANO, José Luis: "La censura española en la época franquista: un libro de Manuel Luis Abellán", insula, n. ${ }^{\circ} 423,1982$, p. 14.

CANO, José Luis: "Censura y política de los escritores españoles", Ínsula, n. ${ }^{\circ} 348,1975$, p. 8.

CELA, C. José: "Tribulaciones de un manuscrito", El País, 4/3/1982.

CARCEDO, Pilar: "La censura en la poesía de Blas de Otero", Cuardenos Interdisciplinarios de Estudios Literarios, $n .^{\circ} 52$.

CONTE, Rafael: "De la censura política a la censura de mercado", Letra Internacional, $n .{ }^{\circ} 21-22$, 1991, pp. 12-13.

ERviti, J. Luis: "La censura de libros en la España franquista: el miedo a la cultura», El Viejo Topo, n. ${ }^{\circ} 13,1977$, pp. 29-32. 
GATE, A., "Diálogos sobre la cultura española", El Urogallo, n. ${ }^{13}$ 1972, pp. 80-91.

Goytisolo, Juan, El furgón de cola, Seix Barral, Barcelona, 1976. (pp. 51-61: "Los escritores españoles frente al toro de la censura" y pp. 63-73: «La literatura perseguida por la política»).

LECHNER, J.: El compromiso en la poesía española en el siglo XX, Univers Press, Leiden, 1975. pp. 142-146.

León Murciego, Pablo: La previa censura y prohibición de libros eclesiásticos y las penas contra los infractores de las leyes de la Iglesia en tal materia, Universitas Lateranenssis, Zaragoza, 1959. 160 pp. (pp. 148-160).

MASSOT i MUNTANER, Josep: Cultura i vida a Mallorca entre la guerra y la postguerra (19301950), Publicaciones de I Abadia de Montserrat, Barcelona, 1978 (Cap. VII, sobre publicaciones clandestinas).

MASSOT I MUNTANER, Josep: “La represa del llibre català a la postguerra", Els Marges, n. ${ }^{\circ} 17$, 1979, pp. 88-102.

MONTERO, Isaac: "Prólogo" de la novela Alrededor de un día de abril.

Pecellin Lancharo, Manuel: "Escritores extremeños víctimas de la censura", Rev. de Estudios Extremeños, n. ${ }^{\circ}$ 51,1995, pp. 823-832.

Rev. Camp de l'arpa: “Issac Montero, un largo aliento", n. ${ }^{\circ} 93-94,1981$, pp. 46-49.

Rev Mundo: "Pascual Duarte y la censura", n. ${ }^{\circ} 1.513,1969$.

SAMSO LLENAS, Joan: “L'activitat editorial en catala entre 1939 i el 1951 ", Afers, n. ${ }^{\circ} 22,1995$, pp. 555-569.

Santoro, J. C.: El delito de traducir, Univ. de León, 1985, pp. 93-102 y 139-144.

SAVATER, Fernando: "Ángeles decapitados. La desertización cultural bajo el franquismo", Claves de la Razón Práctica, $n .^{\circ}$ 59, 1996, pp. 8-13.

SOlé I Sabaté, Josep y VILlarroya, Joan: Cronología de la repressió de la llengua i la cultura catalanes, 1936-1975, Curial, Barcelona, 1994. 246 pp.

TORRES, Estanislau: Les tisores de la censura: el règim franquista contra l'autor i contra Manuel de Pedrolo, Pere Calders, Guillem Viladot, Monserrat Roig y Victor Mora, Estanislau Torres, Lleida, 1995. $63 \mathrm{pp}$

VILLANUEVA, Tino: "Censura y creación: dos poemas subversivos de Ángel González", Hispanic Journal, n. ${ }^{\circ} 51,1983$, pp. 49-72.

\section{REFERENCIAS NO LOCALIZADAS}

ABELLAN, M. L.: "He bajado a los sótanos de la censura y lo he copiado todo", Rev. Actual, n. 32, 1982.

Abellan, M. L.: “Acotaciones al fenómeno censorio", en Nierderehe, H. J., Akten des Deutschen Hispanistentages, Helmut Buske Verlag, Hamburg, pp. 342-353 (Texto de la ponencia en las Jornadas de Hispanistas alemanes en Wolfenbuttel).

ABELLAN, M. L.: "Apunts sobre la censura literària a Catalunya", Rev. de Catalunya, $n .{ }^{\circ} 27$.

ALPERT, Michael: "Translation and the Censor in Spain", Levende-Sprachen, n. ${ }^{\circ} 23,1978$, pp. 180-182.

HURTLEY, Jacqueline A.: "Translation in Postwar Spain: Twixt Survival and interior Exile", Cuadernos Interdisciplinarios de Estudios Literarios, n. 12.

La Prade Douglas, E.: "The Censorship for whom the Bell tolls in Spain", Rev. North Dakota Quarterly, n. ${ }^{\circ} 60,1992$, pp. 151-158.

LEFERE, Robin: "La censura franquista de las novelas de Claude Simón», en Juan CASTiLlo Bravo (ed.), Actas del II Coloquio sobre los Estudios de Filología francesa en la Universidad Española, pp. 409-414.

LEVINEL GOULD, Linda: "The Censored Sex: Woman as Author and Character in Franco's Spain", in MILLER-BETB (ed.), Women in Hispanic Literature: Icons and Fallen Idols, Univ. of California, 1983, pp. 289-315.

O CONNOR, Evelyn: Spanish Censorship (1938-1981): Reform in an Authoritarian state, Univ. of Conecticut, 1995. $214 \mathrm{pp}$.

Torrealdal Nabea, J. M.: Euskararen zapalkuntza, Jakin, n. ${ }^{\circ} 24,1982$. 